\title{
A Multi-Attribute Decision Making for Electrician Selection using Triangular Fuzzy Numbers Arithmetic Approach
}

\author{
Wiwien Hadikurniawati \\ Faculty of Information Technology \\ Universitas Stikubank \\ Semarang, Indonesia
}

\author{
Retantyo Wardoyo \\ Department of Computer Science and Electronics \\ Universitas Gadjah Mada \\ Yogyakarta, Indonesia
}

\begin{abstract}
This study uses an approach of fuzzy multi attribute decision making in determining alternatives to solve the selection problem of the electrician through a competency test. Competency test consists of several tests of knowledge, skills and work attitude. The parameters of decision making is used to choose the best alternative written test, test of theoretical knowledge, practice knowledge test and oral test. Linguistic values expressed by triangular fuzzy numbers is used to represent the preferences of decision makers so that the uncertainty and imprecision in the selection process can be minimized. Aggregation results are represented using triangular fuzzy numbers. The output of this selection process is the best alternative obtained using triangular fuzzy numbers arithmetic approach.
\end{abstract}

Keywords-multi-attribute decision making; triangular fuzzy number; fuzzy arithmetic; electrician

\section{INTRODUCTION}

National development will boost economic growth and competitiveness in the world market. The developments affect the increased needs of the elements associated with infrastructure development, one of which is the human resources in the form of labor. Indonesia has a large number of workers. For this purpose, the quality of Indonesian human resources in various sectors and regions, need to be improved and optimized for utilization [1]. Improving the quality of human resources is very important for experts in construction industry. Labor skills are important part in the implementation of a construction project. Job skills suitability possessed by workers with job skills required by the labor service user is needed to increase employment opportunities [2]. Professional construction sector worker has a reliable ability, ethical, and highly competitive.

The government realizes the importance of human resource competencies in the field of electricity. The government creates it through Law No. 15 on Electricity. The government has drawn up Government Regulation No. 3 of 2005 as an amendment to Government Regulation No. 10 of 1989 About the Provision and Use of Electric Power, which in Article 21 paragraph 9 states that "Every technician who worked in the electricity business is required to have a certificate of competence". The electrician should do several competency tests to obtain a certificate of competence. Competency test consists of knowledge, skills and attitude tests. The tests of knowledge, skill, and attitude obtained from several tests, both written and oral tests as well as practice of skill [2].

The decision-making is a research group developed over the last twenty years, while research on the theory and method of group decision-making has always received attention from researchers in the world $[3,4]$. Multi attribute decision making (MADM) is used to solve the problem in selecting the optimal alternative out of several alternatives related to attributes. The decision maker in the MADM process often takes the form of the linguistic variables. It occurs because of the complexity and uncertainty of the objective things and the ambiguity of human thinking [5]. Multi-attribute decision making method makes the decision maker to be able to determine the appropriate alternative. MADM technique is a popular technique and widely used in many fields of science, namely engineering, economics, management, transportation planning, etc [6].

The fuzzy set theory has been applied in many fields, for example operation research, management theory etc. The fuzzy numbers and fuzzy values are suitable for representing uncertain information; they are used in many applications [7].

At present, if decision information, often refers to attribute value, is given in the form of precise value, the multi attribute decision methods is relativelly perfect.

The complexity and uncertainty of objective things and fuzziness of human thinking in many actual decision making are difficult to give the explicit attribute weight, this kind of multi attribute decision making having incomplete information has been worth studying.

The process of selecting a qualified electrician must be precise, accurate and qualified to be able to achieve the expected outcome is to get the best electrician appropriate to their parameters. Decision making method can solve that problem. Based on the idea, decision making approach is proposed to identify qualified electricians according to their parameters.

In this paper, attribute value are given in the form of Triangular Fuzzy Numbers (TFN), calculate the rank of alternatives according to arithmetic approximation. 
The rest of the papers are organized as follows, section 2 describes related works of the research. In the section 3 triangular fuzzy numbers and fuzzy multi-attribute approach are summarized. In this section, methodology for each technique is also given. Section 4 discusses a case study, analysis, and result of this research. The conclusions are presented in Section 5.

\section{RELATED WORK}

The purpose of multi attribute decision making is reaching a decision by choosing the best alternative from many candidates [8]. The attribute or criteria can be the one causes some benefits or the one that causes cost. Decision making comprised of four steps: 1. Acquisition of information, 2. Decision making model, 3. Acquisition of decision results, 4. Ranking alternatives in a sequence [9]. Hopfe [10] proposed design assessment uncertainty in decision making. This decision making using AHP approach and the case is focused on discrete decision. The key performance indicators are used as a preference in this case.

Dongjing [11] proposed method for decision making, compute the distance between each alternative and positive, negative ideal point of interval numbers, then finds out each alternative's closeness degree for ideal point.

Wibowo [12] used a fuzzy multi-criteria approach in the group decision making to increase the confidence level of the decision maker or the decision maker in solving the problem of selection of suppliers. Fuzzy linguistic variables are used to represent subjective assessment decision makers. The uncertainty can be minimized by fuzzy linguistic variable. Hegazy [13] explained how to solve the problem of uncertainty in the medical world, especially mental health issues using a fuzzy set approach.

Fuzzy multi attribute decision making (FMADM) is used to resolve the problems with the appropriate decision-making approach. FMADM describes rational decisions in situations of uncertainty given in the form of linguistic values. Fuzzy numbers represent the values of linguistic. Researchers typically use triangular fuzzy numbers or trapeziodal [14]. Bekheet [14] proposed polygon fuzzy number (PFN) for decision makers to express their own linguistic. FMADM methods based on comprehensive satisfaction evaluatives that are derived from the preferences of decision maker, is presented to solve the decision data sampling problems in a fuzzy situation. The decision data and weights of all attributes take the form of generalized trapezoidal fuzzy numbers (GTFN) [15].

In this paper, selection of the best alternative is obtained using fuzzy multi attribute decision making methods. The proposed methods use triangular fuzzy numbers and fuzzy arithmetic approach to select electrician.

\section{METHODS}

\section{A. Fuzzy Number}

A fuzzy number is a generalization of a regular, real number in the sense that it does not refer to one single value but rather to a connected set of possible values, where each possible value has its own weight between 0 and 1. Fuzzy number is expressed as a fuzzy set a fuzzy interval in real number. The boundary of this interval is ambiguous; the interval is also a fuzzy set. Generally a fuzzy interval is represented by two end points $a_{1}$ and $a_{2}$ and a peak point $a_{2}$ as $\left[\mathrm{a}_{1}, \mathrm{a}_{2}, \mathrm{a}_{3}\right]$ [16-18].

\section{B. Triangular Fuzzy Number}

Triangular fuzzy number is more popular because of its ease of the arithmetic operations. The arithmetic operations are addition, subtraction, multiplication, division, reciprocal, geometric mean, etc. Such operations enable the decision makers to determine the rank of alternative [16].

Triangular Fuzzy Numbers (TFN) is a fuzzy number represented by three values, namely $A=\left(a_{1}, a_{2}, a_{3}\right)$. It can be defined as shown in (1).

$$
\mu_{(A)}(x)= \begin{cases}0, & x<a_{1} \\ \frac{x-a_{1}}{a_{2}-a_{1}}, & a_{1} \leq x \leq a_{2} \\ \frac{a_{3}-x}{a_{3}-a_{2}}, & a_{2} \leq x \leq a_{3} \\ 0, & x>a_{3}\end{cases}
$$

This presentation is expressed as membership functions as shown in the Fig.1.

The crisp interval got by $\alpha$-cut operation, interval $A_{a}$ is obtained as follows $\forall \alpha \in[0,1]$ from

$$
\frac{a_{1}^{(}{ }^{(\alpha)}-a_{1}}{a_{2}-a_{1}}=a, \quad \frac{a_{3}-a_{3}^{(\propto)}}{a_{3}-a_{2}}=\propto
$$

And then obtained :

$$
a_{1}^{(\propto)}=\left(a_{2}-a_{1}\right) \propto+a_{1}
$$

The formula of $\mathrm{A}_{\alpha}$ obtained as shown in (4).

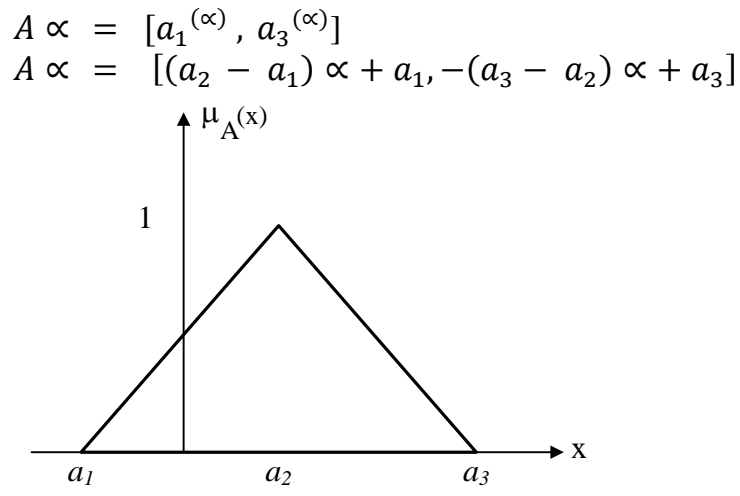

Fig. 1. Triangular Fuzzy Number $A=(a 1, a 2, a 3)$

\section{Fuzzy Arithmetic}

Basic arithmetic operation on fuzzy number is an extension of the concept of basic arithmetic operations in general by using the degree of membership. Some important properties of operations on the triangular fuzzy number are $[17,18]$

1) The result of the addition or subtraction between the triangular fuzzy numbers is in the form of triangular fuzzy numbers 
2) The result of multiplication or division between the triangular fuzzy numbers is not a form of triangular fuzzy numbers. Operations of multiplication or division results can be converted into triangular fuzzy numbers through value approach.

3) Operation max or min did not produce the form of triangular fuzzy numbers

Triangular Fuzzy Numbers Operation

1) Addition

This operation does not use the membership function. For example, $A$ and $B$ are triangular fuzzy number $A=\left(a_{1}, a_{2}, a_{3}\right)$, $\mathrm{B}=\left(\mathrm{b}_{1}, \mathrm{~b}_{2}, \mathrm{~b}_{3}\right) . \mathrm{A}+\mathrm{B}$ are calculated using (5).

$$
\begin{aligned}
& A+B=\left(a_{1}, a_{2}, a_{3}\right)(+)\left(b_{1}, b_{2}, b_{3}\right) \\
& A+B=\left(a_{1}+b_{1}, a_{2}+b_{2}, a_{3}+b_{3}\right)
\end{aligned}
$$

2) Substraction

If $A=\left(a_{1}, a_{2}, a_{3}\right)$ and $B=\left(b_{1}, b_{2}, b_{3}\right) . A-B$ are calculated using (6)

$$
\begin{aligned}
& \mathrm{A}-\mathrm{B}=\left(\mathrm{a}_{1}, \mathrm{a}_{2}, \mathrm{a}_{3}\right)(-)\left(\mathrm{b}_{1}, \mathrm{~b}_{2}, \mathrm{~b}_{3}\right) \\
& \mathrm{A}-\mathrm{B}=\left(\mathrm{a}_{1}-\mathrm{b}_{1}, \mathrm{a}_{2}-\mathrm{b}_{2}, \mathrm{a}_{3}-\mathrm{b}_{3}\right)
\end{aligned}
$$

3) Approximation of Multiplication

There are triangular fuzzy number $\mathrm{A}=\left(\mathrm{a}_{1}, \mathrm{a}_{2}, \mathrm{a}_{3}\right)$ and $\mathrm{B}=$ $\left(b_{1}, b_{2}, b_{3}\right)$.

The main concern is $\alpha$-cuts of two fuzzy numbers,

$A_{\alpha}=\left[\left(a_{2}-a_{1}\right) \alpha+a_{1},-\left(a_{3}-a_{2}\right) \alpha+a_{3}\right]$

$\mathrm{B}_{\alpha}=\left[\left(\mathrm{b}_{2}-\mathrm{b}_{1}\right) \alpha+\mathrm{b}_{1},-\left(\mathrm{b}_{3}-\mathrm{b}_{2}\right) \alpha+\mathrm{b}_{3}\right]$

Multiply $\mathrm{A}_{\alpha}$ with $\mathrm{B}_{\alpha}$ which are 2 crisp intervals, where for all $\alpha \in[0,1]$, that elements of each interval are positive numbers. The formula of multiplication approximation as shown in (8).

$\mathrm{A}_{\alpha}(\cdot) \mathrm{B}_{\alpha}=\left[\left(\mathrm{a}_{2}-\mathrm{a}_{1}\right) \alpha+\mathrm{a}_{1},-\left(\mathrm{a}_{3}-\mathrm{a}_{2}\right) \alpha+\mathrm{a}_{3}\right](\cdot)\left[\left(\mathrm{b}_{2}-\right.\right.$

$\left.\left.b_{1}\right) \alpha+b_{1},-\left(b_{3}-b_{2}\right) \alpha+b_{3}\right]$

The result of multiplication approximation $\mathrm{A}_{\alpha}(\cdot) \mathrm{B}_{\alpha}$ determined by $\alpha=0$ and $\alpha=1$.

\section{4) Approximation of Division}

Value of A (/) B can be expressed in a triangular fuzzy number. The way to determine the division is similar with the multiplication. First step is divide interval $\mathrm{A}_{\alpha}$ by $\mathrm{B}_{\alpha}$.

For $\alpha \in[0,1]$, the formula is shown in (9).

$$
\begin{gathered}
\mathrm{A}_{\alpha}(/) \mathrm{B}_{\alpha}=\left[\left(\mathrm{a}_{2}-\mathrm{a}_{1}\right) \alpha+\mathrm{a}_{1} /-\left(\mathrm{b}_{3}-\mathrm{b}_{2}\right) \alpha+\mathrm{b}_{3},-\left(\mathrm{b}_{3}-\mathrm{b}_{2}\right) \alpha\right. \\
\left.+\mathrm{b}_{3} /\left(\mathrm{b}_{2}-\mathrm{b}_{1}\right) \alpha+\mathrm{b}_{1}\right]
\end{gathered}
$$

The result of division approximation $\mathrm{A}_{\alpha}(\cdot) \mathrm{B}_{\alpha}$ determined by $\alpha=0$ and $\alpha=1$.

\section{Fuzzy Multi Attribute Approach}

Decision makers often face doubt and uncertainty in expressing subjective perceptions or judgments, uncertainty in decision making. Fuzzy set theory is used to express the linguistic terms of decision-makers to resolve the uncertainty, ambiguity and subjectivity of human judgment [19].
The decision makers are influenced by uncertainties and imprecision in giving their subjective assessment. This uncertainty occurs because the decision makers are not fully confident in their assessments so that their judgments are represented by fuzzy numbers in linguistic form [20]. Linguistic variables represented by fuzzy numbers, which represent a subjective assessment decision to minimize the uncertainty and imprecision in the selection process. The steps of fuzzy multi attribute decision making (FADM) are:

\section{1) Problem Representation}

a) Identification of goals and decision alternative is determining the highest rank of alternative.

b) Parameter Identification

c) Building a hierarchical structure of these problems.

\section{2) Evaluation of Fuzzy Set}

a) Choosing the rating set for the weights parameter and the degree of fitness for each alternative with its parameters. $W_{i}$ is the weight for parameter $P_{t} . S_{i t}$ is a fuzzy rating for the fitness degree of decision alternative $A$ and parameter $P_{t} . \quad F_{i}$ is a fuzzy match index of alternative $A i$ which represents the fitness degree of alternative decisions. $F_{i}$ is derived from the aggregation $S_{i t}$ and $W_{t}$, where $i=1,2,3, \ldots$ $n$ and $t=1,2,3, \ldots k$

b) Evaluating parameter weights and fitness degrees of any alternative parameters.

Aggregating the parameter weights and the fitness degree of each alternative with its parameters using fuzzy arithmetic, as shown in (10).

$F_{i}=\left[\left(S_{1 i} \otimes W_{1}\right) \oplus\left(S_{2 i} \otimes W_{2}\right) \oplus \ldots \oplus\left(S_{i k} \otimes W_{k}\right)\right]$

\section{3) Selecting Alternatives}

a) Prioritizing decision alternative based on the results of aggregation. Priority aggregation results are used to determine the ranking of decision alternatives. This aggregation results represented as triangular fuzzy numbers.

b) Choose a decision alternative with the highest priority as the optimal alternative.

\section{CASE STUdy}

The proposed model is applied to solve the problem of the electrician selection.

\section{A. Problem Representation}

The problems in the selection of electrician aim to get experts who have parameters as per the requirements of the Agency for Construction Services. The electricians fulfill the administrative requirements before taking the competency test. The competency test consists of 4 exam materials and they are parameter of decision making. These parameters include P1 (written test), P2 (test of theoretical knowledge), P3 (practice knowledge test), and P4 (oral test). The electricians will receive a certificate of competence after they have passed a competency test. The problem in the selection of electrician can be represented in Fig. 2. 


\section{B. Evaluation of Fuzzy Set}

There are linguistic variables that represent the importance weight for each parameter. Each weight represented by a triangular fuzzy numbers as follows:

$\mathrm{T}_{\text {(importance) }} \mathrm{W}=\{\mathrm{VL}, \mathrm{L}, \mathrm{M}, \mathrm{H}, \mathrm{VH}\}$

$\mathrm{VL}=$ Very Low, $\mathrm{L}=$ Low, $\mathrm{M}=$ Medium, $\mathrm{H}=$ High, $\mathrm{VH}=$ Very High. Each weight represented by a triangular fuzzy numbers as follows:

- $\mathrm{VL} \quad=(0,0,0.25)$

- $\mathrm{L} \quad=(0,0.25,0.5)$

- $\mathrm{M} \quad=(0.25,0.5,0.75)$

- $\mathrm{H} \quad=(0.5,0.75,1)$

- $\mathrm{VH}=(0.75,1,1)$

The fitness degree of alternatives and decision parameter as follows :

$$
\mathrm{T}_{\{\text {fitness })} \mathrm{S}=\{\mathrm{VP}, \mathrm{P}, \mathrm{M}, \mathrm{G}, \mathrm{VG}\}
$$

$\mathrm{VP}=$ Very Poor, $\mathrm{P}=$ Poor, $\mathrm{M}=$ Medium, $\mathrm{G}=$ Good, $\mathrm{VG}=$ Very Good. Each weight represented by a triangular fuzzy numbers as follows:

$$
\begin{array}{lll}
\text { - } & \mathrm{VP} & =(0,0,0.25) \\
\text { - } \mathrm{P} & =(0,0.25,0.5) \\
\text { - } \mathrm{M} & =(0.25,0.5,1) \\
\text { - } & \mathrm{G} & =(0.5,0.75,1) \\
\text { - } & \mathrm{VG} & =(0.75,1,1)
\end{array}
$$

The rating for each decision parameter is shown in Table 1. The fitness degree of decision parameter and alterative are shown in Table 2

The next step is to determine the value of a fuzzy fitness. The values obtained by aggregating the alternative weight of importance degree on each parameter as shown in Tables 1

\begin{tabular}{|c|c|c|c|c|}
\hline \multirow{2}{*}{ Alternative } & \multicolumn{4}{|c|}{ Parameter } \\
\hline & $P 1$ & $P 2$ & $P 3$ & P4 \\
\hline Electrician 1 & $\mathrm{M}$ & $\mathrm{G}$ & $\mathrm{P}$ & $\mathrm{P}$ \\
\hline Electrician 2 & $\mathrm{P}$ & $\mathrm{P}$ & $\mathrm{M}$ & $\mathrm{G}$ \\
\hline Electrician 3 & $\mathrm{G}$ & VG & $\mathrm{G}$ & $\mathrm{G}$ \\
\hline Electrician 4 & $\mathrm{M}$ & $\mathrm{M}$ & $\mathrm{P}$ & M \\
\hline Electrician 5 & $\mathrm{P}$ & $\mathrm{G}$ & $\mathrm{G}$ & $\mathrm{M}$ \\
\hline Electrician 6 & $\mathrm{G}$ & $\mathrm{G}$ & $\mathrm{G}$ & $G$ \\
\hline Electrician 7 & $\mathrm{P}$ & M & VP & VP \\
\hline Electrician 8 & VP & $\mathrm{G}$ & $\mathrm{G}$ & $\mathrm{G}$ \\
\hline Electrician 9 & $\mathrm{VG}$ & M & $\mathrm{G}$ & $\mathrm{G}$ \\
\hline Electrician 10 & $\mathrm{P}$ & $\mathrm{G}$ & $\mathrm{G}$ & $\mathrm{G}$ \\
\hline
\end{tabular}
and Table 2

TABLE I. IMPORTANCE RATE FOR EACH PARAMETER

\begin{tabular}{|l|l|l|l|l|}
\hline Parameter & P1 & P2 & P3 & P4 \\
\hline Importance rate & L & H & VH & M \\
\hline
\end{tabular}

TABLE II. FITNESS RATE OF EACH ALTERNATIVE TOWARD PARAMETERS

Alternative 1 (Electrician 1)
- Alternative fitness rating A1 (electrician 1) of the first parameter is Medium $(\mathrm{M})=(0.25,0.5,0.75)$ and the importance rate for parameter 1 is Low $(\mathrm{L})=(0,0.25$, $0.50)$.

Fuzzy fitness value is determined using approximation of multiplication on fuzzy arithmetic, as follows:

$$
\begin{aligned}
& \mathrm{A}=(0.25,0.5,0.75) \quad \mathrm{B}=(0,0.25,0.5) \\
& \mathrm{A}_{\alpha}=[(0.5-0.25) \alpha+0.25,-(0.75-0.5) \alpha+0.75] \\
&= {[0.25 \alpha+0.25,-0.25 \alpha+0.75] } \\
& \mathrm{B}_{\alpha}=[(0.25-0) \alpha+0,-(0.5-0.25) \alpha+0.5] \\
&=[0.25 \alpha+0,-0.25 \alpha+0.5] \\
& \mathrm{A}_{\alpha}(.) \mathrm{B}_{\alpha}=[0.25 \alpha+0.25,-0.25 \alpha+0.75](\cdot)[0.25 \alpha+0, \\
&\quad-0.25 \alpha+0.5] \\
&=[(0.25 \alpha+0.25)(0.25 \alpha+0), \quad(-0.25 \alpha+0.75)(- \\
&\quad 0.25 \alpha+0.5)] \\
&=\left[0.0625 \alpha^{2}+0.0625 \alpha, 0.0625 \alpha^{2}-\right. \\
& \\
&\quad 0.125 \alpha+0.1875]
\end{aligned}
$$

If $\alpha=0$, then $\mathrm{A}_{\alpha}(\cdot) \mathrm{B}_{\alpha}=[0,0.1875]$

If $\alpha=1$, then $\mathrm{A}_{\alpha}(.) \mathrm{B}_{\alpha}=[0.125,0.125]=0.125$

Triangular Fuzzy Number $(\mathrm{TFN})$ of $\mathrm{A}_{\alpha}(\cdot) \mathrm{B}_{\alpha} \cong(0,0.125$, 0,1875).

- Alternative fitness rating A1 (electrician 1) of the second parameter is Good $(\mathrm{G})=(0.5,0.75,1)$ and the importance rate for parameter 2 is $\operatorname{High}(\mathrm{H})=(0.5$, $0.75,1)$.

Fuzzy fitness value is determined using approximation of multiplication on fuzzy arithmetic, as follows:

$$
\begin{aligned}
\mathrm{A}= & (0.5,0.75,1) \quad \mathrm{B}=(0.5,0.75,1) \\
\mathrm{A}_{\alpha}=[(0.75-0.5) \alpha+0.5,-(1-0.75) \alpha+1] & \\
= & {[0.25 \alpha+0.5,-0.25 \alpha+1] } \\
\mathrm{B}_{\alpha}=[(0.75-0.5) \alpha+0.5,-(1-0.75) \alpha+1] & \\
= & {[0.25 \alpha+0.5,-0.25 \alpha+1] } \\
\mathrm{A}_{\alpha}(\cdot) \mathrm{B}_{\alpha}= & {[0.25 \alpha+0.5,-0.25 \alpha+1](\cdot)[0.25 \alpha+0.5} \\
& -0.25 \alpha+1] \\
= & (0.25 \alpha+0.5)(0.25 \alpha+0.5),(-0.25 \alpha+1) \\
& (-0.25 \alpha+1)] \\
= & {\left[0.0625 \alpha^{2}+0.025 \alpha+0.25,0.0625 \alpha^{2}-0.5 \alpha+1\right] }
\end{aligned}
$$

If $\alpha=0$, then $\mathrm{A}_{\alpha}(\cdot) \mathrm{B}_{\alpha}=[0.25,1]$

If $\alpha=1$, then $\mathrm{A}_{\alpha}(\cdot) \mathrm{B}_{\alpha}=[0.5625,0.5625]=0.5625$

Triangular Fuzzy Number (TFN) of $A_{\alpha}(\cdot) B_{\alpha} \cong(0.25,1$, 0,5625).

- Alternative fitness rating A1 (electrician 1) of the third parameter is Poor $(\mathrm{P})=(0,0.25,0.5)$ and the importance rate for parameter 3 is Very High $(\mathrm{VH})=$ $(0.75,1,1)$.

Fuzzy fitness value is determined using approximation of multiplication on fuzzy arithmetic, as follows:

$$
\begin{aligned}
& \mathrm{A}=(0,0.25,0.5) \quad \mathrm{B}=(0.75,1,1) \\
& \mathrm{A}_{\alpha}=[(0.25-0) \alpha+0,-(0.5-0.25) \alpha+0.5] \\
&=[0.25 \alpha+0,-0.25 \alpha+0.5] \\
& \mathrm{B}_{\alpha}=[(1-0.75) \alpha+0.75,-(1-1) \alpha+1] \\
&=[0.25 \alpha+0.75,-0 \alpha+1] \\
& \mathrm{A}_{\alpha}(.) \mathrm{B}_{\alpha}=[0.25 \alpha+0,-0.25 \alpha+0.5](\cdot)[0.25 \alpha+0.75,- \\
&0 \alpha+1]
\end{aligned}
$$




$$
\begin{aligned}
= & {[(0.25 \alpha+0)(0.25 \alpha+0.75),(-0.25 \alpha+0.5)(-} \\
& 0 \alpha+1)] \\
= & {\left[0.0625 \alpha^{2}+0.1875,-0.25 \alpha+0.5\right] }
\end{aligned}
$$

If $\alpha=0$, then $\mathrm{A}_{\alpha}(\cdot) \mathrm{B}_{\alpha}=[0.1875,0.5]$

If $\alpha=1$, then $\mathrm{A}_{\alpha}(\cdot) \mathrm{B}_{\alpha}=[0.25,0,25]=0.25$

Triangular Fuzzy Number (TFN) of $\mathrm{A}_{\alpha}$ (.) $\mathrm{B}_{\alpha} \cong$ $(0.1875,0,25,0,5)$.

- Alternative fitness rating A1 (electrician 1) of the fourth parameter is Poor $(\mathrm{P})=(0,0.25,0.5)$ and the importance rate for parameter 4 is Medium $(\mathrm{M})=$ $(0.25,0.5,0.75)$.

Fuzzy fitness value is determined using approximation of multiplication on fuzzy arithmetic, as follows:

$$
\begin{aligned}
& \mathrm{A}=(0,0.25,0.5) \quad \mathrm{B}=(0.25,0.5,0.75) \\
& \mathrm{A}_{\alpha}=[(0.25-0) \alpha+0,-(0.5-0.25) \alpha+0.5] \\
& =[0.25 \alpha+0,-0.25 \alpha+0.5] \\
& \mathrm{B}_{\alpha}=[(0.5-0.25) \alpha+0.25,-(0.75-0.5) \alpha+0.75] \\
& =[0.25 \alpha+0.25,-0.25 \alpha+0.75] \\
& 0.25 \alpha+0.75] \\
& =\left[\begin{array}{ll}
(0.25 \alpha+0)(0.25 \alpha+0.5), & (-0.25 \alpha+0.5)(-
\end{array}\right. \\
& 0.25 \alpha+0.75)] \\
& =\quad\left[0.0625 \alpha^{2}+0.0625 \alpha, \quad 0.0625 \alpha^{2}-\right.
\end{aligned}
$$

$0.3125 \alpha+0.375]$

If $\alpha=0$, then $\mathrm{A}_{\alpha}(\cdot) \mathrm{B}_{\alpha}=[0,0.375]$

If $\alpha=1$, then $\mathrm{A}_{\alpha}(\cdot) \mathrm{B}_{\alpha}=[0.125,0.125]=0.125$
Triangular Fuzzy Number (TFN) of $\mathrm{A}_{\alpha}(\cdot) \mathrm{B}_{\alpha} \cong(0$, $0.125,0,375)$

Triangular Fuzzy Number (TFN) of the alternative weight to other parameters can be determined with the same steps as the previous calculation. The fuzzy fitness value calculation results of all alternative towards parameter can be seen in Table 3 .

\section{Ranking of Alternatives}

The ranking is determined from the alternatives that have the largest parameter to the smallest alternatives. The result obtained is shown in Table 4.

Based on the results from the calculation, it is obtained that an electrician 3 has the highest value and has top rank.

\section{CONCLUSION}

The process of evaluating and determining an electrician in the competency test involves many parameters. This study uses triangular fuzzy number arithmetic approach for decision-making to solve the problem of determining an electrician in the competency test. Linguistic values expressed by triangular fuzzy number is used to represent the preferences of decision makers so that the uncertainty and imprecision in the selection process can be minimized. Aggregation results are represented using triangular fuzzy numbers. The selection results are obtained in the form of ranking the final value of the electrician. They are used to recommend experts in electrical field who has the highest level of competence.

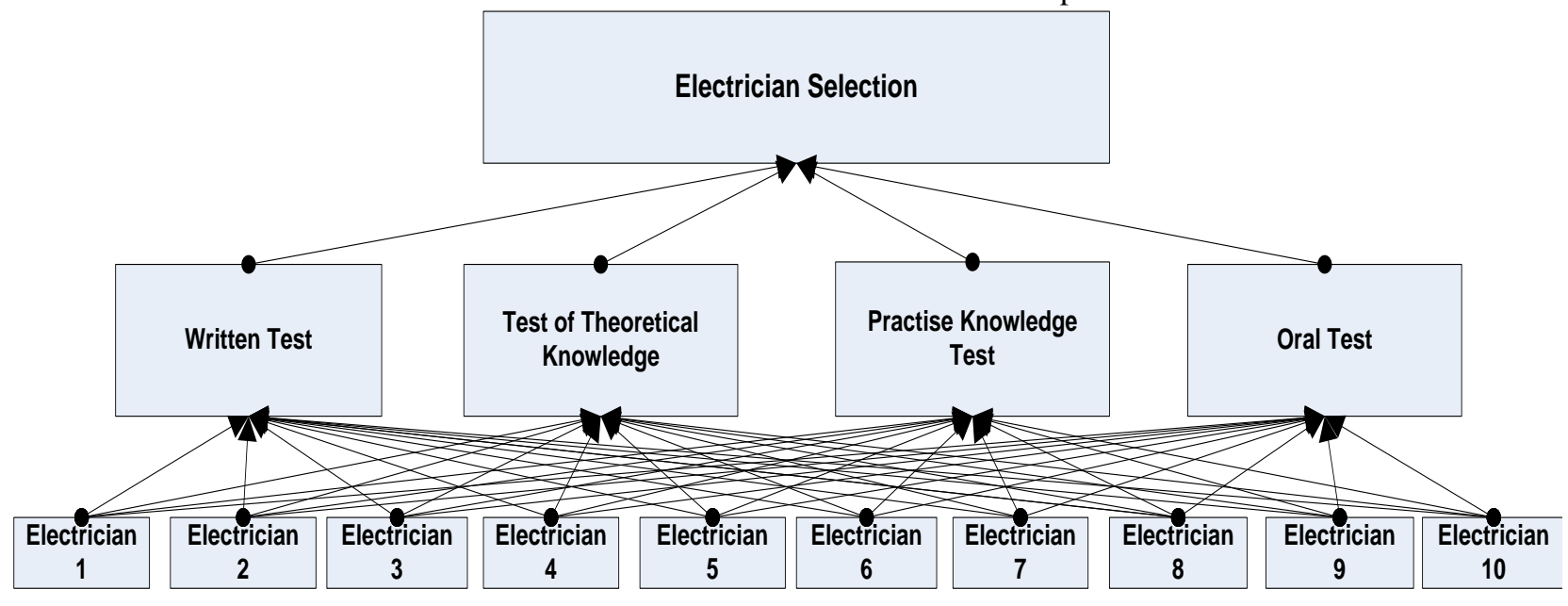

Fig. 2. Structure to select electrician

TABLE III. The FuzZy Fitness VALUE

\begin{tabular}{|l|l|l|l|l|}
\hline \multirow{2}{*}{ Alternative } & Parameter & $\boldsymbol{P 2}$ & $\boldsymbol{P 3}$ & $\boldsymbol{P 4}$ \\
\cline { 2 - 5 } & $\boldsymbol{P 1}$ & $(0.25,0.5625,1)$ & $(0.1875,0.25,0.5)$ & $(0,0.125,0.375)$ \\
\hline Electrician 1 & $(0,0.125,0.1875)$ & $(0,0.1875,0.5)$ & $(0.1875,0.5,0.75)$ & $(0.125,0.375,0.75)$ \\
\hline Electrician 2 & $(0,0.0625,0.25)$ & $(0.375,0.75,1)$ & $(0.375,0.75,1)$ & $(0.125,0.375,0.75)$ \\
\hline Electrician 3 & $(0.125,0.1875,0.5)$ & $(0.25,0.5625,1)$ & $(0.1875,0.25,0.5)$ & $(0.0625,0.25,0.5625)$ \\
\hline Electrician 4 & $(0,0.125,0.375)$ & $(0.25,0.5625,1)$ & $(0.375,0.75,1)$ & $(0.125,0.375,0.75)$ \\
\hline Electrician 5 & $(0,0.0625,0.25)$ & $(0.25,0.5625,1)$ & $(0.375,0.75,1)$ & $(0,0,0.1875)$ \\
\hline Electrician 6 & $(0,0.1875,0.5)$ & $(0.125,0.375,0.75)$ & $(0,0,0.25)$ & $(0.125,0.375,0.75)$ \\
\hline Electrician 7 & $(0,0.0625,0.25)$ & $(0.25,0.5625,1)$ & $(0.375,0.75,1)$ & $(0.125,0.375,0.75)$ \\
\hline Electrician 8 & $(0,0,0.125)$ & $(0.125,0.375,0.75)$ & $(0.375,0.75,1)$ & $(0.125,0.375,0.75)$ \\
\hline Electrician 9 & $(0.875,0.25,0.75)$ & $(0.25,0.5625,1)$ & $(0.375,0.75,1)$ & $(0.125,0.375,0.75)$ \\
\hline Electrician 10 & $(0,0.0625,0.25)$ & & \\
\hline
\end{tabular}


TABLE IV. The Result of Alternative RANKInG

\begin{tabular}{|l|l|l|}
\hline Alternative & Weight & Rank \\
\hline Electrician 1 & $(0.109375,0.265625,0.515625)$ & 7 \\
\hline Electrician 2 & $(0.078125,0.28125,0.5625)$ & 8 \\
\hline Electrician 3 & $(0.25,0.515625,0.8125)$ & 1 \\
\hline Electrician 4 & $(0.125,0.296875,0.609375)$ & 6 \\
\hline Electrician 5 & $(0.1875,0.4375,0.75)$ & 3 \\
\hline Electrician 6 & $(0.15625,0.375,0.671875)$ & 5 \\
\hline Electrician 7 & $(0.0625,0.203125,0.5)$ & 9 \\
\hline Electrician 8 & $(0.1875,0.421875,0.71875)$ & 4 \\
\hline Electrician 9 & $(0.203125,0.4375,0.8125)$ & 2 \\
\hline Electrician 10 & $(0.1875,0.4275,0.75)$ & 3 \\
\hline
\end{tabular}

$$
\text { REFERENCES }
$$

[1] Direktorat Jenderal Pembinaan Pelatihan dan Produktivitas, Departemen Tenaga Kerja dan Transmigrasi, "Pedoman Penyelenggaraan Sistem Pelatihan Kerja Nasional di Daerah," 2000.

[2] Lembaga Pengembangan Jasa Konstruksi Nasional, "Rancangan Standar Kompetensi Kerja Khusus", 2010.

[3] X. Chen and L. Ma, "An Analytic Method far Consensus Analyisis in Group Experts'Judgments Based on Numerical Decision Matrix Preference Information", Fifth International Conference on Fuzzy Systems and Knowledge Discovery, IEEE, doi:10.1109/FSKD.2008.502, 2008, pp. 176-180.

[4] P. Liu and Y. Su, "Multiple Attribute Decision Making Method Based on the Trapezoid Fuzzy Linguistic Hybrid Harmonic Averaging Operator", Informatica, Vol. 36, 2012, pp. 83-90.

[5] P. Dongjing, "A New Method for Fuzzy Multiple Attribute Decision Making based on Interval Numbers", International Forum on Information Technology and Applications, IEEE Computer Society, doi:10.1109/IFITA.2009.141, 2009, pp. 408-411,

[6] L. Fan and F. Zuo, "Research on Multi-Attribute Decision Making Method Based on AHP and Outranking Relation", Workshop on Power Electronics and Intelligent Transportation System, IEEE, doi:10.1109/PEITS.2008.42, 2008, pp. 227-232.

[7] A.N. Gani and S.N.M. Assarudeen, "A New Operation on Triangular Fuzzy Number for Solving Fuzzy Linear Programming Problem", Applied Mathematical Sciences, Vol.6, No. 11, 2012, pp. 525-532.

[8] K.T. Cho, "Multicriteria Decision Methods : An Attempt to Evaluate and Unify", Mathematical and Computer Modelling, Elsevier, 2003, pp. 1099-1119.

[9] Y. Dong and H. Zhang, "Multiperson Decision Making with Different Preference Representation Structures : A Direct Consensus Framework and Its Properties". Knowledge Based System, doi:10.1016/j.knosys.2013.09.021, Elsevier, 2013.

[10] C.J. Hopfe, G.L.M. Augenbroe, J.L.M Hensen, "Multi-Criteria Decision Making Uncertainty in Building Performance Assesment", Building and Environment, Elsevier, vol.69, doi:10.1016/j.buildenv.2013.07.019 , 2013, pp. 81-90.
[11] P. Dongjing, "A New Method for Fuzzy Multiple Attribute Decision Making based on Interval Numbers", Internatioal Forum on Information Technology and Applications, doi: 10.1109/IFITA.2009.141, IEEE Computer Society, 2009, pp. 408-411.

[12] S. Wibowo, “A Fuzzy Multicriteria Group Decision Making Approach for Improving the Degree of Confidence in Supplier Selection”, Fourth International Symposium on Computational Intelligence and Design, doi: 001.10.1109/ISCID.2011.122. IEEE Computer Society, 2011, pp. 83-86.

[13] S. Hegazy, et.al, "Modulating Membership Grades to Gain Consensus for Fuzzy Set Uncertainty Values in Clinical Decision Support System", Third International Conference on Advances in Human-Oriented and Personalized Mechanisms, Technologies and Services, IEEE Computer Society, doi: 10.1109/CENTRIC.2010.27, 2010, pp. 40-45.

[14] S. Bekheet, “An Enhanced Fuzzy Multi Criteria Decision Making Model with a proposed Polygon Fuzzy Number", International Journal of Advanced Computer Sience and Applications (IJACSA), Vol. 5, No. 5, 2014, pp. 118-121.

[15] X. Yu, M. Li, Z. Ping, "Multi-Attribute Group Decision Making Based on Biased Informaton Sampling Model and Generalized Trapezoidal Fuzzy Numbers", 12th International Conference on Computer and Information Technology, doi: 10.1109/CIT.2012.44, 2012, pp. 109-114.

[16] F. Herrera, E.H.Viedma, "Linguistic Decision Analysis : Steps for Solving Decision Problems Under Linguistik Information", Fuzzy Sets and Systems 115, PII: S0165-0114(99)00024-X, 2000, pp. 67-82.

[17] K.H. Lee, "First Course on Fuzzy Theory and Applications", Springer, ISSN.16-15-3871, 2005.

[18] L.X. Wang, "A Course in Fuzzy Systems and Control", Prentice-Hall International Inc, 1997.

[19] A. Sanayei, S.F. Mousavi, C.A. Shahmirzadi, "A Group Based Fuzzy MCDM for Selecting Knowledge Portal System", World Academy of Science, Engineering and Technology 52, 2009, pp. 455-452.

[20] M. Tavana, M.A. Sodenkamp, “A Fuzzy multi-criteria Decision Analysis Model for Advanced Technology Assesment at Kennedy Space Center", Jounal Operational Research Soc, DOI. 10.1057/jors. 2009.107. Vol.61, 2010, pp. 1459-1470. 